\title{
Intérpretes do Brasil: influências na origem do pensamento econômico brasileiro*
}

\author{
Interpreters of Brazil: Influences on the origin of Brazilian \\ Economic Thought
}

\author{
Carla Curty, Maria Malta e Bruno Borja $\star \star$
}

\begin{abstract}
Resumo: O final do século XIX e o início do século XX foram marcados por uma profusão de tentativas de dar um significado autônomo à sociabilidade que funcionava no interior das fronteiras do que se entendia como Brasil. Descobrir o sentido do Brasil era algo tão forte no pensamento social da época que as expressões econômicas, políticas e artísticas foram marcadas por essa questão, sem necessariamente buscarem uma referência nacionalista ou xenófoba, apesar de em alguns casos passar por elas. Tomando como referência o tempo histórico entre os movimentos abolicionistas e a Era Vargas, o objetivo deste texto é recuperar no pensamento dos intérpretes do Brasil os elementos da configuração das estruturas econômico-sociais brasileiras que ganham centralidade em suas visões sobre o Brasil e influenciam a origem do pensamento econômico brasileiro.
\end{abstract}

Palavras-chave: Intérpretes do Brasil. História do pensamento econômico brasileiro. Estruturas econômicas e sociais.

\begin{abstract}
The late nineteenth and early twentieth century were marked by a profusion of attempts to give meaning to the sociability existing within the boundaries of what was understood as Brazil. Discover the meaning of Brazil was something so strong in social thought at the time that economic, political and artistic expressions were marked by this issue, without necessarily seeking nationalist or xenophobic references, although in some cases exploring them. Taking the historical time between the abolitionist movements and the Vargas Era as reference,
\end{abstract}

\footnotetext{
^ Submissão: 10/07/2020 | Aprovação: 22/11/2020 | DOI: 10.29182/hehe.v24i2.751

$\star \star$ Respectivamente: (1) Professora do Departamento de Ciências Econômicas e Exatas, Instituto Três Rios, Universidade Federal Rural do Rio de Janeiro (UFRRJ), Brasil | E-mail: carla_curty@yahoo.com.br | ORCID: 0000-0002-3052-9779 | (2) Professora Associada do Instituto de Economia, Universidade Federal do Rio de Janeiro (UFRJ), Brasil | E-mail: mariammalta@yahoo.com.br | ORCID: 0000-00025538-940X | (3) Professor do Departamento de Ciências Econômicas da Universidade Federal Rural do Rio de Janeiro (UFRRJ), Brasil | E-mail: borja.bruno@gmail.com | ORCID: 0000-0002-4813-7001
} 
this paper aims to recover in the thought of the interpreters of Brazil the configuration elements of Brazilian economic and social structures that gained centrality in their views and influenced the origin of Brazilian economic thought.

Keywords: Interpreters of Brazil. Brazilian history of economic thought. Economic and social structures.

JEL: B19; B29; N96 
"A publicação de um livro não pode ser abordada como um evento, mas sim o resultado de um processo histórico."

Tamas Szmrecsányi (1999)

\section{Introdução}

Pode-se indicar dois momentos históricos fundacionais referidos a problemáticas concretas que colocam a sociedade brasileira em posição crítica em relação à própria realidade e provocam um pensamento brasileiro desenvolvido a partir da reflexão sobre sua condição social e processo de formação histórica. Esses momentos são, no final do século XIX, a abolição da escravidão, solapando as bases da forma política do Império, e, no início no século XX, a transição histórica do Brasil, de país agrário-exportador para urbano-industrial, tendo como ponto de referência a década de 1930.

Em ambos os casos, trata-se de épocas em que o processo de transformação produtiva teve implicações definitivas na estruturação da sociedade brasileira. No primeiro caso, a abolição da escravidão significava, do ponto de vista do capital, uma gigantesca expropriação de riqueza, e do ponto de vista do trabalhador, a necessidade de se estabelecer um novo quadro de relações político-jurídicas sobre o trabalho no país. Os trabalhadores escravizados conquistaram sua liberdade pessoal (abolição da escravidão), passaram formalmente a ter direito à voz, a formular e apresentar propostas de mudança social, mas ainda lhes faltava obter efetivamente todos esses direitos. Por isso, a luta por seus direitos, no caminho da libertação efetiva, deveria continuar. ${ }^{1}$

No segundo caso, a transformação social em curso tinha como origem a transmutação do capital agrário em capital industrial, o que implicava uma reorganização da tradicional sociedade rural brasileira, tornando-se progressivamente uma sociedade urbana, questionando todas as relações sociais predominantes e difundindo dentro das fronteiras brasileiras o padrão industrial das relações sociais capitalistas, inclusive naquilo que concerne às lutas por direitos do trabalhador.

Além disso, o movimento que se desenrola no Brasil diz respeito à percepção dos limites do Estado liberal acompanhado da instituição do mercado autorregulável, que havia orientado a ação do Estado brasileiro desde a

\footnotetext{
${ }^{1}$ Uma boa referência sobre história das lutas dos trabalhadores brasileiros desde o início do século XX está em Mattos (2009).
} 
independência. A percepção desses limites levou o pensamento brasileiro à controvérsia da fundação de um Estado assentado, efetivamente, sobre a sociedade brasileira. É nesse bojo que se desenrola o necessário debate sobre processo de formação econômica e social no Brasil.

Assim, nosso objetivo neste artigo é recuperar no pensamento de alguns dos intérpretes do Brasil os elementos da configuração das estruturas econômicas e sociais brasileiras que ganham centralidade em suas visões sobre o Brasil e influenciam a origem do pensamento econômico brasileiro.

\section{A noção de intérprete do Brasil}

Coutinho ([1988] 2011) identifica o "mal-estar" do final do século XIX e do início do século XX no Brasil, afirmando algo que vale para todo o pensamento radical ${ }^{2}$ dessa época. $\mathrm{O}$ autor afirma que mesmo quando trata do passado, aquele pensamento tem sempre em vista a investigação do presente como história, o que implica para ele uma análise dialética da gênese e das perspectivas desse presente. Ainda que poucos autores da época possam reivindicar a dialética como lógica, em muitos casos utilizando métodos autodeclarados como positivistas, não é dificil identificá-la, como uma invasão da lógica da história real, objeto do trabalho desses autores, no seu pensamento e formulação.

A primeira geração desses intérpretes está preocupada com a gestação do Brasil republicano da barriga do império escravocrata, como uma formação que precisava finalmente dar conta de sua identidade nacional não colonial. Essa é a geração de Joaquim Nabuco, André Rebouças, Castro Alves, Euclides da Cunha, Manoel Bomfim e Machado de Assis. Em Nabuco e Euclides, percebe-se o importante questionamento do status quo, identificado pelos modernistas como macaqueador ${ }^{3}$ do pensamento europeu ou da República Federativa dos Estados Unidos da América. Essa geração trazia à tona a ina-

\footnotetext{
2 Antonio Candido, em seu artigo "Radicalismos", de 1986, estabelece uma categorização dos pensadores no Brasil como podendo pertencer a três categorias segundo seu posicionamento político e social. Para Candido, os pensadores poderiam ser conservadores, revolucionários ou radicais. O pensamento radical seria um modo progressista de reagir ao estímulo dos problemas sociais prementes, um pensamento gerado na pequena burguesia e em setores esclarecidos das classes dominantes que se identifica em parte com os interesses das classes trabalhadoras, mas que se opõe à sua classe apenas até certo ponto. $\mathrm{O}$ radical pensaria os problemas e as soluções na escala da nação como um todo, passando por cima do antagonismo entre classes. Ainda assim, Candido afirma que o radical teve por muitas vezes papel transformador no pensamento brasileiro, pois foi capaz de avançar realmente, ou servir de fermento transformador em alguns contextos.

${ }^{3}$ Sérgio Buarque de Holanda populariza esta terminologia para referência ao pensamento da elite brasileira em seu artigo “Ariel” (1920).
} 
dequação das instituições brasileiras à sua realidade social, fruto de um pensamento formulador totalmente copista (como descrevia Euclides quando se referia às populações do litoral $)^{4}$, ou decadente e dependente, como classificava Nabuco ([1884], 2012).

A geração dos anos 1920 e 1930 tem como ansiedade principal, em suas diferentes orientações teórico-políticas, a tentativa de compreender a formação socioeconômica do Brasil no contexto do início da transição de uma sociedade agrário-exportadora para uma sociedade urbano-industrial. Essa geração formada pelos autores modernistas, na literatura, encontrava interseções com os pensadores das estruturas sociais, como no caso de Sérgio Buarque de Holanda. Desse grupo também fizeram parte autores mais conservadores, como Gilberto Freyre, mas cuja postura de revelação do padrão da formação social tornava radical.Vale destacar também a presença de Caio Prado Júnior, que é identificado por vários autores ${ }^{5}$ como o autor que elaborou uma das primeiras tentativas bem-sucedidas de aplicar o método de Marx para a análise do Brasil, um marco no marxismo brasileiro. ${ }^{6}$ Todos esses pensadores, das duas gerações, denunciavam a desconexão das formas institucionais vigentes no Brasil em relação à sociedade que efetivamente produzia suas relações sociais em território brasileiro.

O campo que ficou conhecido como interpretações do Brasil apareceu, conforme destaca Ricupero (2008), exatamente neste período iniciado com o debate abolicionista e republicano, no final do século XIX, desdobrando-se com o estabelecimento e o desenvolvimento mais amplo da universidade no Brasil, nas décadas de 1920 e 1930. É possível identificar nesses autores a questão da formação do Brasil como uma questão de fundo de seus trabalhos, isto é, preocupavam-se com o debate do estabelecimento de um quadro social nacional mais autônomo que se contraporia à origem colonial do Brasil, marcada por diversos tipos de domínio, como cultural, político e econômico. Buscando compreender o Brasil de seu tempo, geralmente suas obras tratam dos três momentos históricos, o presente, o passado e o futuro, isto é, começam com um grande balanço histórico - foco no passado -, analisam

\footnotetext{
${ }^{4}$ Ver Cunha (1902, seção II, item V). Para uma análise das implicações do termo ver Lima (2009).

${ }^{5}$ Entre os comentadores que sustentam essa opinião destaca-se: Francisco Iglésias, (1982); Carlos Nelson Coutinho ([1988] 2011) e Bernardo Ricupero (2008).

${ }^{6}$ Octávio Brandão, em 1926, publicara Agrarismo e industrialismo: ensaio marxista-leninista sobre a revolta de São Paulo e a guerra de classes no Brasil, que pode ser considerada uma primeira interpretação marxista do Brasil (Pinheiro, 2018). No entanto, há polêmicas sobre a obra; o próprio autor, nos anos 1950, reconhece os limites do seu trabalho em virtude da aplicação mecânica de uma visão stalinista do marxismo.
} 
como os elementos desse balanço histórico e do processo de formação contribuíram para a construção do Brasil - o presente - e fecham com um programa político sobre como superar os problemas do país - futuro.

Nosso ponto é que um intérprete do Brasil tem consigo uma missão intelectual, pois busca, por meio da pesquisa histórica, compreender a realidade presente do país. Dessa forma, não se pretende afirmar que no final do século XIX ou nos anos 1920 e 1930 se apresente o primeiro pensamento propriamente brasileiro, autônomo em relação às teorias dos principais centros mundiais. O que se pretende é identificar um tipo de interpretação que dará destaque, ainda que de formas diferentes, à estrutura produtiva para tentar analisar e compreender o Brasil e sua formação. Ou ainda, desejamos afirmar que os autores desses estudos devem ser entendidos como intérpretes do Brasil por colocarem a formação da nação em perspectiva histórica. E, nesse processo, esses autores constroem uma interpretação do Brasil.

Cabe ainda a proposição de mais uma hipótese: se o cerne do movimento interpretativo desses autores é a produção e as relações sociais estruturais e superestruturais a ela relacionadas, poderíamos identificar esse momento como fundacional do pensamento econômico brasileiro.

Tomamos o método apresentado por Curty e Malta (2019) para a compreensão e sistematização da história do pensamento econômico brasileiro. Mais especificamente, a processualidade do pensamento, em que diferentes experiências históricas, teóricas e posicionamentos políticos, sociais e ideológicos configuram fortes influências sobre a configuração do pensamento. Entendemos que os âmbitos teórico, histórico e ideológico não podem ser dissociados e que a história do pensamento econômico deve ser contada e sistematizada a partir de controvérsias. Também abordamos o pensamento econômico de forma mais ampla do que as visões economicistas e positivistas de compartimentação do campo da economia levam a crer. O entendimento de objeto do pensamento econômico aqui trabalhado se constitui das questões ligadas aos elementos estruturais da produção: o trabalho, a tecnologia, a disponibilidade de recursos naturais, associados à organização da sociedade de classes. Compreendemos os autores aqui analisados como parte da história do pensamento econômico brasileiro, podendo incluí-los em seu movimento de origem.

Se tomarmos emprestado de Ricupero (2008) a ideia de que a formação seja um tema recorrente em um país com passado colonial e persistente situação de dependência, e se somarmos a noção de que a missão intelectual de 
um intérprete do Brasil é compreender a formação da nação em perspectiva histórica, encontramos um típico desafio de cientista social em geral, e de economista marxista em particular: compreender a realidade para transformá-la.

É bem verdade que no caso brasileiro essa missão intelectual não foi tomada apenas, e nem mesmo em sua maioria, por autores marxistas. Nem por isso os trabalhos desenvolvidos pelos intérpretes do Brasil deixam de ter seu viés radical ou crítico, na medida das questões que se propõem a responder. Mesmo assim, tomar como objeto o pensamento econômico brasileiro e afirmar o método do materialismo histórico-dialético como referência é buscar uma forma de análise do pensamento brasileiro poucas vezes utilizada, em especial no campo da economia política.

Por outro lado, a preocupação com o estabelecimento de um quadro social autônomo, que se contrapusesse à situação de subordinação colonial é a chave para um pensamento que coloca no seu centro dinâmico principal o que ocorre internamente no país. Por isso as interpretações do Brasil são marcadas pela análise das formas estruturais da produção social da vida material, que se expressam em determinadas relações sociais necessárias e independentes de sua vontade e às quais correspondem relações de produção referentes a uma determinada fase do desenvolvimento das forças produtivas materiais. Ao mesmo tempo, um intérprete não poderá deixar de perceber que sobre essa estrutura se levanta uma superestrutura jurídica, política e correspondentes formas da consciência social (Marx, [1859] 2008) que necessariamente compõem seu objeto. Assim, as tentativas de interpretar o Brasil não conseguirão escapar das artimanhas de seu objeto e acabarão cedendo lugar, aqui e ali, à dialética, ao radicalismo e à crítica.

Conforme já mencionado, o recorte de Candido (1986) apresenta o radicalismo brasileiro como um conjunto de ideias e atitudes formando um contrapeso ao movimento conservador que sempre predominou no Brasil. Essa versão de radicalismo à brasileira inclui a definição de um modo progressista de reagir ao estímulo dos problemas sociais prementes em oposição ao modo conservador.

O radicalismo contido nas interpretações do Brasil revela-se na preocupação desses autores com a formação da nação. Para compreender a nação que aqui se formara ou que poderia vir a se formar era necessário dispor-se a desvendar a realidade brasileira e propor uma explicação para a formação econômico-social que se apresentava dentro das fronteiras do Estado Nacional. A realidade, a base material, tinha que ser o ponto de partida desses autores e o foi. 
Nessa perspectiva, escolhemos autores representativos das duas gerações mencionadas para destacar como seu pensamento pode ser visto como portador de elementos fundantes do pensamento econômico brasileiro.

\section{A primeira geração de intérpretes: os abolicionistas e os trabalhadores}

Joaquim Nabuco foi o abolicionista mais referido em seu tempo, apesar de ter feito parte de um movimento muito mais amplo que possuía facetas mais extremadas e mais moderadas que a posição que assumia. Nascido em 1849 em Pernambuco, ano seguinte e local da Revolução Praieira, a última das revoltas provinciais de caráter liberal, foi filho de uma família abastada, dona de terras e escravos, e frequentava os salões da corte. Era um jovem de seu tempo, formado em direito no seio da doutrina liberal e americanista que frequentava os debates de sua geração. $\mathrm{Na}$ faculdade de Direto em São Paulo foi colega de sala e debate de Castro Alves, Rui Barbosa, Rodrigues Alves e Afonso Pena. Porém, acabou por se transferir para a Faculdade de Direito do Recife para terminar seus estudos e escandalizou a elite local, por defender, em um júri, uma pessoa escravizada negra que assassinara o seu senhor.

Mesmo sendo queridinho dos salões do império, tal atitude criou uma grande oposição da elite local ao seu trabalho e seu pensamento, só conseguindo emprego em 1876, quando foi nomeado para posto diplomático por intermédio da mãe. Porém, o movimento da realidade brasileira o colocou no centro da ação nos anos posteriores quando foi eleito deputado pelo Partido Liberal e instalou em sua residência a Sociedade Brasileira Contra a Escravidão. Assim, ele aprofundou as divergências com o seu partido e inviabilizou a sua reeleição. Sem mandato, foi passar uma temporada em Londres, onde escreveu O abolicionismo e se preparou para, em 1885, eleger-se para um novo mandato como abolicionista e monarquista federalista, tomando o modelo liberal inglês como referência política.

Em O abolicionismo, Nabuco denuncia o senso comum sobre a escravidão no Brasil no século XIX. Afirmava que se encontrava nos jornais e em toda a sociedade "declarações repetidas de que a escravidão entre nós é um estado muito brando e suave para o escravo, de fato melhor para este que para o senhor, tão feliz pela descrição, que se chega a supor que os escravos, se fossem consultados prefeririam o cativeiro à liberdade"; e acidamente concluía: 
"o que tudo prova, apenas, que os jornais não são escritos por escravos, nem por pessoas que se hajam mentalmente colocado, por um segundo, na posição deles" (Nabuco, [1884] 2012, p. 97).

Esse é o ponto de partida para uma reflexão que contribuirá de forma decisiva para a compreensão do que era e do que poderia ser uma nação brasileira marcada pelo signo da escravidão. Para Nabuco, um país cujos principais produtores da riqueza e a maior parte da população era formada por "uma classe sem direito algum: a dos escravos"7 (Nabuco, [1884] 2012, p. 98) estaria condenada à decadência.

Sua questão é que os escravizados constituem o maior grupo formador do povo brasileiro e sua condição de submissão ao terror e à falta de qualquer tipo de direito é tão nociva e destruidora para eles próprios quanto para a formação da nação. De seu ponto de vista, a primeira "vingança das vítimas" da escravidão é que os principais habitantes, o futuro do povo brasileiro, seria composto na sua maioria de descendentes de pessoas escravizadas, ${ }^{8}$ classe submetida pela brutalidade. Além disso, segundo Nabuco, a escravidão não era nociva apenas ao escravo, mas também aos senhores, que se degradavam pela brutalização de seus costumes na relação com os escravos. Nas palavras do autor: a consequência para a formação do povo era "o cruzamento dos caracteres da raça negra com os da branca, tais como se apresentam na escravidão; a mistura da degradação servil de uma, com a imperiosidade brutal da outra" (Nabuco, [1884] 2012, p. 107).

Ainda, alertava para o fato de que a pessoa escravizada era o grande sustentador da produção no Brasil, e não apenas nas fazendas. Era a pessoa escravizada quem cuidava da família do senhor, quem ensinava seus filhos, quem transmitia parte relevante da moral e dos costumes aos cativos e aos livres.

\footnotetext{
${ }^{7}$ Nabuco ([1884] 2012) nos informa que não há menção às pessoas escravizadas em qualquer código da nação, seja na constituição de 1824 ou em qualquer outro ponto da legislação. Não havia nem mesmo um código negreiro. Segundo Martins (2017), embora seja verdade que não havia um código negreiro que versasse sobre a administração e tratamento das condições de vida da população em condição de escravidão, em Portugal havia ampla legislação sobre o tráfico de pessoas em condição de escravidão, incluindo dois códigos negreiros ligados a essa questão, um no século XVII, e o outro no século XIX. Esse ordenamento jurídico que visava regulamentar o trabalho do regime escravocrata na colônia incluía leis, cartas de lei, alvarás, regimentos, estatutos, cartas régias, decretos, provisões, avisos, resoluções e outras peças sobre a administração e a economia escravista de Portugal na colônia.

${ }^{8}$ Os intérpretes do Brasil abordados neste artigo utilizam sempre a palavra escravo para se referir a uma pessoa escravizada. Estamos de acordo com o entendimento atual sobre a condição de pessoas escravizadas, e não de escravos. No entanto, esta não é a posição desses intérpretes, o que gera uma dificuldade significativa de expressão. Assim, optamos por manter, na maioria dos casos, a referência a escravos, no sentido de expressar a posição dos intérpretes.
} 
O território também sofria com a organização escravista da produção, pois o regime da terra sob a escravidão era uma divisão de todo solo explorado em certo número de grandes propriedades rurais que se caracterizavam como verdadeiras colônias penais, refratárias ao progresso, espaços senhoriais em que imperava uma só vontade, a do senhor. O problema dessa construção social identificada por Nabuco é que essa estrutura se mantém pela dependência e por isso não pode buscar progredir ou beneficiar a população livre que nela mora sob o risco de destruir a base social sobre a qual se assenta. Assim, o território tende a criar formações isoladas e autossuficientes em um nível de subsistência muito básico, com poder descentralizado local e refratárias ao funcionamento e às normas do Estado Nacional. Dessa forma, gesta-se uma nação em que faltam centros locais e cidades, havendo um embotamento do comércio e das profissões liberais e não havendo espaço para as classes médias.

Unindo esses fatores em sua análise, o abolicionista aponta para uma síntese sobre a economia de uma nação escravista afirmando que "o resultado final daquele sistema [escravista] é a pobreza e a miséria do país. Nem é de admirar que a cultura do solo por uma classe sem interesse algum no trabalho que lhe é extorquido dê estes resultados" (Nabuco, [1884] 2012, p.116).

Assim, podemos afirmar que Nabuco contribui e influencia o pensamento econômico brasileiro na medida em que identifica na forma da organização do trabalho a fonte das mazelas e das possibilidades de melhoria da formação social e econômica do Brasil.

Euclides da Cunha representa uma segunda fase dessa primeira geração: a fase republicana. Se Nabuco se preocupava em modificar as bases da monarquia que defendia, Euclides buscava construir os argumentos de sustentação na nova ordem republicana da nação. ${ }^{9}$

Euclides é um personagem cheio de contrastes e contradições, mas sem dúvida um autêntico republicano. Nasceu em 1866, na Província do Rio de Janeiro e ficou órfão aos 3 anos de idade, tendo sido criado pelas tias. Estudou em S. Fidelis, depois na Bahia e finalmente no Rio de Janeiro, até que em

\footnotetext{
${ }^{9}$ Nessa geração vale destacar também o trabalho de Manoel Bomfim, que foi um autor importante para as interpretações do Brasil a partir de 1905, porém com maior expressividade com suas obras publicadas nos anos 1920 até sua morte em 1932. Manoel Bomfim tem uma obra marcada pelo antirracismo, pelo anticonservadorismo e pelo anticolonialismo, sendo um autor totalmente contracorrente e bastante ostracizado em seu tempo e na atualidade, não tendo sua obra se conformado como uma grande referência para os debates do pensamento social brasileiro, especialmente no campo da economia.Vale, no entanto, disputá-lo, ampliando a pesquisa sobre sua obra, para compor o panteão dos intérpretes do Brasil.
} 
1886 prestou exames na Escola Politécnica, mas abandona o curso um ano depois, transferindo-se para a Escola Militar. A Escola militar era em sua época um polo irradiador de ideias republicanas, marcando a influência de Benjamin Constant, positivista e que viria a ser um dos líderes da Proclamação da República, em seu pensamento. Sua adesão às ideias republicanas e antiescravistas o levou a protagonizar um episódio que acabou marcando sua vida e lhe dando fama. Para impedir a participação dos cadetes em uma manifestação de apoio a Lopes Trovão, notório republicano que voltava da Europa, foi marcada uma inspeção às tropas pelo Ministro da Guerra,Tomás Coelho. Durante a revista, Euclides saiu de forma, tentou quebrar o espadim e o atirou aos pés do Ministro, desacatando-o. Procurou-se abafar o ocorrido, mas Euclides foi desligado do Exército, em dezembro de 1888, sob a alegação de incapacidade fisica. No entanto, famoso pelo episódio do espadim, foi convidado por Júlio de Mesquita, ainda em 1888, para escrever em O Estado de São Paulo (na época, A Província de São Paulo), onde passa a defender abertamente as ideias republicanas. Com a Proclamação da República, é anistiado, reintegrado à Escola Militar (na sua turma) e forma-se oficial. Em 1896 abandona definitivamente o Exército e vai trabalhar como engenheiro civil em São Paulo, quando eclode a Guerra de Canudos, que muda novamente sua vida, na medida em que, no ano seguinte, parte para a Bahia, como enviado especial do Estadão.

A visão de Euclides era fortemente influenciada pela ciência da sua época, mas carregava uma contradição. A ciência que conhecia era altamente justificadora, em última instância, da empresa colonial e da exploração dos povos da periferia, apresentava os conceitos de clima e de raça para afirmar a superioridade dos países do centro capitalista sobre o resto do mundo e afirmava que o clima dos trópicos jamais permitiria formas modernas de organização social, econômica ou política. De outro lado, sua vivência pessoal e histórica o fazia não aceitar essas ideias inteiramente, mesmo não dispondo dos instrumentos para criticá-las ou superá-las. Nelson Werneck Sodré chega a observar sobre esse tema que "existe em Euclides um dualismo singular" (Werneck Sodré, 1961, p. 142), que afasta seu testemunho de sua reflexão.

É possível perceber esse dualismo nas linhas de Os sertões. Se seu trabalho é organizado nos marcos da teoria da história de Von Martius (raça, meio e momento histórico como determinantes do movimento da história), sua solução para a superação dos problemas que identifica no Brasil contemporâneo está vinculada a uma visão de que o mestiço brasileiro concebido no clima do sertão é o herói nacional. 
O sertanejo de Euclides representa o setor da classe trabalhadora que não encontra lugar na produção central de sua época. Seu modo de produção social da vida aparece como uma forma de resistência aos limites do clima e da sociedade que o colocam em situação de expropriação permanente. Sua descrição da sociedade vigente em Canudos mistura um horror pela forma bárbara de sociabilidade com uma admiração com seu potencial de criar a vida a partir de condições hostis. Organizações sociais do tipo de Canudos seriam formas de resistência do expurgo do setor da produção central.

Contradições à parte, Euclides acaba encaminhando sua análise para afirmar que uma nação efetivamente brasileira e capaz de realizar um projeto nacional autônomo teria que se originar na população sertaneja. De seu ponto de vista, as organizações sociais do tipo que se encontrava no litoral limitavam-se a copiar as formas europeias, destinando o país à submissão permanente.

Diferentemente de Nabuco, com sua visão liberal de sociedade e progresso, a nação de Euclides não poderia vir de fora, ou de setores copistas situados no litoral, teria que se organizar a partir da produção de resistência do sertanejo.

\section{A segunda geração (1920-1930): os demiurgos e a centralidade das relações sociais de produção}

A geração seguinte vai discutir o Brasil republicano que, influenciado pela então recente Primeira Guerra Mundial e pela crise de 1929, começa a organizar no entorno das cidades da República pequenas manufaturas de produção de bens de consumo dos trabalhadores, tais como têxteis, alimentos processados e olarias. A discussão dos intérpretes desse período já ganha a dinâmica daquilo que Francisco de Oliveira e Antonio Candido acabaram por intitular de demiurgos do Brasil. A ideia de demiurgos considera que esses autores estariam discutindo um novo Brasil, que pretendia estar na rota de se tornar um país majoritariamente urbano e industrial.

A tríade tradicionalmente eleita para representar os intérpretes dessa geração são Gilberto Freyre, Sérgio Buarque de Holanda e Caio Prado Júnior. Em comum, esses autores possuem a eleição de um ponto de partida para buscar compreender o Brasil: a colonização portuguesa. Nenhum deles vai buscar as origens do Brasil nos povos originários existentes no território quando os portugueses chegaram. Essa opção revela um entendimento espe- 
cífico do que deve ser considerado como origem do Brasil: ocupação portuguesa nos trópicos, seja ela "cordial", como quer Sérgio Buarque, seja ela exploratória, como aponta Caio Prado.

O presente é descrito por cada um desses intérpretes como um momento de crise, já bem diferente do Brasil da época da colonização portuguesa. Gilberto Freyre fala de uma nação patriarcal ameaçada por conta de uma "reeuropeização" do país, uma tentativa de importar as formas sociais e políticas vigentes na Europa do início do século XX e que não correspondiam ao processo histórico vivido pelo Brasil. Já Sérgio Buarque descreve um país em crise por estar em contradição entre o que é e o que precisa ser. O Brasil de Buarque de Holanda é um território de desterro do europeu que aqui se constitui enquanto homem cordial e se organiza pelo personalismo, patriarcalismo e autoritarismo, porém que precisa se tornar uma democracia. Caio Prado ainda afirma algo diferente sobre a crise que também identifica no presente do país. Indica haver um desacordo entre o sistema econômico legado pela colônia e a nova necessidade de uma nação livre e politicamente emancipada, uma verdadeira contradição entre o grau de desenvolvimento das forças produtivas e as relações sociais de produção.

Mais interessante ainda é o futuro imaginado por esses autores como a verdadeira nação brasileira. Gilberto Freyre aponta que a revelação do verdadeiro Brasil está posta. Seria a sociedade patriarcal a ser recuperada de nossas origens coloniais, já adaptadas pelo tempo de relação entre as várias raças na forma de produção social da vida no Brasil. Tal processo, segundo Freyre, ocorreria de forma original e diferente da europeia. Sérgio Buarque de Holanda olha para o passado de forma muito semelhante a Freyre. Seu homem cordial tem vários pontos de contato com o senhor da Casa Grande do pernambucano. No entanto, afirma não haver ônus em perder as raízes do Brasil para que este país possa se constituir como um espaço democrático verdadeiramente nacional. Pois, em sua concepção, o espaço da política democrática criadora da nação seria urbano e público, que não derivam das raízes por ele identificadas. Caio Prado, por sua vez, radicaliza a ideia de que não há nação no Brasil. Seu ponto é que o futuro do país precisa ser democrático e nacional, sendo necessário fazer uma revolução brasileira para constituir a nação, que não existiria por termos organizado toda a vida orgânica do país voltada para fora.

De nosso ponto de vista, essa geração contribui para o pensamento econômico brasileiro na medida em que dá centralidade à história e às relações 
sociais que se estabeleciam no bojo da organização produtiva do país para sua compreensão.

Casa Grande E Senzala:formação da família brasileira sob regime da economia patriarcal carrega em seu título o recorte que mencionamos. Os espaços sociais indicados no título são os espaços de convivência do privado na estrutura de classe estabelecida pela forma de produção desenvolvida no Brasil. Apesar de um maior interesse pelo detalhamento das relações desenvolvidas no âmbito da família, o trabalho de Freyre abre um caminho novo na historiografia brasileira. Porque até então a história da maioria dos povos limitava-se a episódios grandiosos: era um registro cronológico de guerras e coroações, de atos de heroísmo e rebeldia, ilustrados com monumentos, estátuas equestres e condecorações. Esse novo caminho coloca o povo como o ator da história e põe a história em movimento a partir do modo habitual de se produzir e reproduzir a vida material.

Freyre fez parte de um movimento intelectual que, baseado no trabalho de Franz Boas, criticou com veemência os determinismos biológicos e geográficos, além da crença no evolucionismo cultural. Boas apontava que cada cultura é uma unidade integrada, fruto de um desenvolvimento histórico peculiar. Enfatizou a independência dos fenômenos culturais com relação às condições geográficas e aos determinantes biológicos, afirmando que a dinâmica da cultura está na interação entre os indivíduos e a sociedade. Freyre, então, propõe substituir o conceito de raça pelo conceito de cultura. No entanto, acaba caindo em um neolamarkianismo ${ }^{10}$ em que as raças se modificam ao se adaptarem ao meio (em especial, ao clima), o que o colocou no campo da tropicologia por algum tempo.

Outro ponto muito interessante do projeto de Freyre que se inicia com Casa Grande E Senzala é o uso de pares antagônicos para compreender a dinâmica brasileira. São exemplos dos pares antagônicos que dão a dinâmica de seu argumento: Casa grande e senzala; cultura europeia e cultura indígena; cultura europeia e cultura africana; o jesuíta e o fazendeiro; economia agrária e economia pastoril; o senhor e o escravo. No entanto, sua apresentação sintética não é exatamente de uma unidade de contrários, mas de um equilíbrio estabelecido entre esses opostos, uma síntese na docilidade acompanhada pelo mando. Estas seriam “duas metades confraternizantes que se vêm mutuamente enriquecendo de valores e experiências diversas", ainda que por meio de

\footnotetext{
${ }^{10}$ Noção neolamarkiana de raça: caracteres adquiridos pelos seres ao se adaptarem ao meio definem sua raça.
} 
descrições de sadismo, violência sexual e submissão. É nesse contexto que aparece a miscigenação como solução para a integração harmônica de contrários no Brasil, como um encontro intercultural nos trópicos. É o encontro entre o português, visto como contemporizador e plástico, um homem sem ideias absolutas nem preconceitos inflexíveis, e as pessoas escravizadas africanas. Esse encontro é tornado possível pelo que Freyre imagina ser a especificidade da escravidão brasileira, que, apesar de violenta, admitiria proximidade e influência recíproca. No entanto, esse é um encontro entre dominantes e dominados, regado de perversão e sadismo, no qual a igualdade nunca se faz presente.

É desse processo de equilíbrio pela dominação que Freyre retira o que considera ser a singularidade da formação social brasileira: a família patriarcal. A referência principal da organização social brasileira, conforme descrita por Freyre, é a unidade produtiva da fazenda, grande produtora da riqueza social. Assim, a família patriarcal e sua fazenda formam a célula social do Brasil. De seu ponto de vista, há uma extraordinária influência da família na organização social brasileira, pois ela reunia em si todas as dimensões da sociedade, dada a distância do Estado português. Ao mesmo tempo, indica que existe uma permanente "ambiguidade" cultural brasileira dada pelo embate entre a tradição patriarcal (séculos XVI, XVII e XVIII) e o processo de ocidentalização influenciado pela Europa "burguesa" (século XIX).

Sérgio Buarque de Holanda tem uma contribuição diferente. Como já adiantamos, nos anos 1930, já era um modernista crítico. Tão crítico que havia sido alijado até mesmo pelos modernistas a partir da publicação de seu texto "O lado oposto e os outros lados", em 1926. Nos anos 1930, vai para Berlim, onde toma contato com a sociologia ensinada e debatida na Alemanha da época - Max Weber, Georg Simmel,Wilhelm Dilthey, Karl Mannheim, György Lukács, Croce,Vico, Krakauer, Sombart, entre outros.É na Alemanha que escreve os textos que seriam publicados como Raízes do Brasil, em 1936. Para Antonio Candido, Sérgio Buarque possui:

A única das explicações do Brasil daquele tempo composta em função do presente. [...] a referência ao presente se orientava por uma percepção aguda da dialética latino-americana em geral, brasileira em particular, da insubordinação e da submissão, cuja consequência política é o jogo de autoritarismo e rompante libertário. (Candido, [1967] 2008, p. 35) 
Teixeira (2002) aponta que o trabalho de interpretação do Brasil de Sérgio Buarque nos anos 1930 pode ser encarado como "meio alemão", pois nutre-se de um hegelianismo difuso e de uma forte influência da escola histórica alemã. Os autores dessa tradição eram críticos ao liberalismo inglês; lutavam pela reforma social, embora, no plano teórico, fossem avessos a receitas (típicas do liberalismo que criticam); recusavam as generalizações amplas, peculiares a todas as filosofias da história: "a própria idéia de uma teoria simples da evolução histórica lhes parecia errônea e não científica" (Teixeira, 2002, p. 65); criticavam análises isolantes dos fenômenos econômicos, acreditando que se perdia a sua essência quando os isolávamos.

O sentido de Raízes do Brasil é avaliar as dificuldades e possibilidades de se estabelecer a democracia no Brasil. Tal como já destacado, Buarque de Holanda parte da colonização portuguesa, no entanto, não se furta a caracterizar o português como um homem socialmente plástico e Portugal como uma nação entre Europa e África. Aponta que o sucesso da colonização portuguesa nos trópicos tem relação com seu desleixo, a disposição de confundir-se com as linhas da paisagem, ao mesmo tempo em que não visa criar nada aqui, apenas explorar comercialmente. Ainda caracteriza a colonização como se assentando sobre a cultura da personalidade, na qual a ética aristocrática de pouco valor ao trabalho criou a dificuldade de fazer vingar o associativismo e a solidariedade, determinando uma prevalência do espaço privado sobre o público. Tal hipertrofia do ambiente doméstico implicaria uma herança rural de forma política autoritária. Essa forma política teria em sua origem a "natureza" do povo brasileiro: a cordialidade. O sentido dessa cordialidade é normativo, implica que os brasileiros obedecem ao imperativo do coração e não a normas impessoais abstratas, tornando a democracia no Brasil "um mal entendido" (Buarque de Holanda, 1936, p. 113), já que o princípio liberal fundamental de que todos são iguais perante à lei fica subordinado aos laços pessoais de origem privada.

Assim, a interpretação do autor surge como um contraponto às visões conservadoras de Oliveira Vianna ${ }^{11}$ e Gilberto Freyre, cuja valorização da he-

${ }^{11}$ É fato que Oliveira Vianna, por conta de seu papel no governo Vargas e sua atuação política na então capital da República, a cidade do Rio de Janeiro, ganhou importância no debate dessa geração. Porém sua adesão às problemáticas e preconceituosas teses racialistas, que ganharam estado de ciência nos anos 1920 , colocou-o ao lado de tudo aquilo que os vitoriosos da Segunda Guerra Mundial se envergonhavam e, por isso, sua herança é muito pouco reivindicada para a caracterização do pensamento atual no Brasil. O conservadorismo passou a ser representado pela tese também autoritária, mas que defendia o mito da democracia racial por meio de uma visão também racista da miscigenação e da absorção do negro na sociedade brasileira, de Gilberto Freyre, deixando de fora os adeptos de Gobineau e da visão das raças como definidora do caráter dos seres humanos e de sua hierarquização social, como Oliveira Vianna. 
rança ibérica é notória. Para Sérgio Buarque, nossa revolução, que estaria em curso e seria lenta e gradual, era a libertação das raízes ibéricas: abrindo espaço para organizações sociais democráticas com conteúdos novos, diferentes dos europeus.

A grande formulação do intérprete é que o Brasil não é suas raízes. $\mathrm{O}$ Brasil é um local de desterro: um projeto de futuro sem passado ou presente, com um povo em eterno movimento indicando que nossa identidade está projetada em um futuro que ainda não se sabe o que é.

Porém, Teixeira (2002) nos faz perceber que exatamente o que dá força à interpretação de Holanda para renovar a trajetória de sua atividade é também a origem de seus limites.

Seu método será sempre o da composição de painéis totalizantes, nos quais a singularidade dos fenômenos contemplados não permite a generalização das leis de movimento; sua visão do presente nunca se apresentará claramente e sua proposta de futuro nunca assumirá contornos concretos, pois supõe um Estado abstrato e virtual visto como realização da liberdade; sua dialética jamais deixará de ser a dialética da razão. (Teixeira, 2002, p. 68)

Podemos agora afirmar que Sérgio Buarque de Holanda influencia o pensamento econômico brasileiro na medida em que abre espaço para a percepção do Brasil como uma formação social nova, não identificável com a europeia, apesar de herdeira e submetida a ela.Afırma nossas relações sociais de produção como específicas e a necessidade de constituí-las como objeto delimitado e a ser analisado com método próprio. Tal postura tem forte reverberação no entendimento, por exemplo, do Brasil como uma estrutura subdesenvolvida, dependente do capitalismo central, porém com história e formação próprias nesse contexto e não como um simples reflexo da economia e das formações sociais europeias.

Entretanto, as influências mais profundas dos intérpretes do Brasil sobre o pensamento econômico brasileiro precisam ser recuperadas no pensamento de Caio Prado Junior. Evolução política do Brasil (1933), seu primeiro texto de intervenção no debate, nos anos 1930, já continha os elementos que se desenvolveram na interpretação histórica dominante sobre a colonização brasileira.

Caio Prado Júnior (1907-1990) foi filho da burguesia cafeeira paulistana, os Silva Prado, recebendo toda criação e educação de sua classe social à época. No entanto, sua trajetória política e intelectual se dá a partir do 
marxismo e da militância no Partido Comunista Brasileiro (PCB), ao qual se filia em 1931 e permanece vinculado ao longo de quase toda a sua vida, ainda que em boa parte de sua trajetória no partido fosse voz dissonante da linha hegemônica. Fortemente influenciado pela efervescência política, intelectual e cultural dos anos 1920 e 1930, cursou Direito na tradicional Faculdade do Largo do São Francisco, entre 1924 e 1928, momento em que inicia sua atuação política direta. Em 1928 ingressou no Partido Democrático (PD), partido de orientação liberal. O PD e Caio Prado Júnior fizeram oposição a Júlio Prestes e apoiaram a candidatura de Getúlio Vargas nas eleições presidenciais de 1930. Havia suspeita de que as eleições haviam sido fraudadas, a fim de colocar Júlio Prestes como vitorioso; Caio Prado Junior apoia ${ }^{12} \mathrm{o}$ movimento armado de contestação ao resultado das eleições de 1930 que leva Vargas ao poder. Mas logo se desilude com os rumos do movimento e do governo, passa a adotar postura mais crítica e radical, ocasião em que se filia ao PCB.

Ao longo dos anos 1930, após a publicação de Evolução política do Brasil (1933), aproxima-se da história e da geografia, participando das aulas dessas áreas na Universidade de São Paulo (USP), recém-fundada à época. Essas áreas marcarão fortemente suas reflexões sobre o Brasil. Nessa época também assume a posição de vice-presidente da seção paulista da Aliança Nacional Libertadora (ANL) e participa da organização de maneira intensa, sendo um dos principais articuladores da ANL no Estado de São Paulo. Logo a ANL é colocada na ilegalidade e desfeita; seus principais militantes, incluindo Caio Prado Júnior, são presos. Caio Prado permanece dois anos na prisão e após sua libertação, exila-se na França entre 1937 e 1939, onde começa a redação de sua obra mais emblemática no que concerne à sua interpretação do Brasil, Formação do Brasil contemporâneo: colônia (1942). Estuda na Sorbonne, aproxima-se do Partido Comunista Francês e participa dos movimentos antifascistas no contexto da Guerra Civil espanhola. No retorno ao Brasil, publica o livro em 1942 e, no mesmo ano, funda a Editora Brasiliense, que será de grande importância para a esquerda e para os intelectuais críticos, em especial os marxistas e comunistas. Nesse retorno ao Brasil, retorna também à militância política, em um contexto delicado, pois o PCB estava na ilegalidade durante a ditadura do Estado Novo.

\footnotetext{
${ }^{12}$ Nesse período, Caio Prado Júnior é preso pela primeira vez. Ao longo de sua vida, por conta de sua militância política, será preso muitas outras vezes (Pericás, 2016).
} 
Muitas das teses de Caio Prado Júnior são tão difundidas que quase mais ninguém sabe que foi ele seu autor. É raro encontrar alguém que ainda pesquise a história econômica do Brasil e pense que houve um passado feudal no país. Ao mesmo tempo, todos percebem a colonização brasileira não como algo particular, mas no contexto da expansão marítima europeia. No entanto, poucos sabem que ambas as noções foram formuladas por Caio Prado Júnior.

Em sua época, essas teses foram recebidas a quente: dentro de seu partido, o Partido Comunista Brasileiro, houve quem afirmasse que "negar restos feudais sem provar [...] é clara manifestação do que se pode chamar ideologia estranha ao proletariado infiltrada no partido" (Martins, 1947). Porém, a questão em Caio Prado era metodológica. Não viu o materialismo histórico como um conjunto de fórmulas com pretenso valor universal e não aceitou as teses da $3^{\text {a }}$ Internacional para os "países coloniais, semicoloniais e dependentes" transmitidas de Moscou para o Bureau Sulamericano da Internacional Comunista (localizado em Montevidéu) e irradiadas de lá como modelo único, recomendando a todos a criação das condições para a realização de uma revolução burguesa. No entanto, nunca foi relativista ou adaptacionista teórico, "até porque se seu marxismo fosse capaz de absorver qualquer forma referente às mais variadas sociedades, não seria mais marxismo, nem mesmo teoria, mas apenas uma expressão quase não mediatizada da realidade" (Ricupero, 2009, p. 230).Assim, Caio Prado Júnior não deixa de afirmar o marxismo como método para a interpretação de diferentes experiências históricas. Realiza o abrasileiramento do marxismo, a tradução dessa teoria para as condições da realidade brasileira.

É a partir dessa interpretação do Brasil, sob a batuta do marxismo, que Prado Júnior coloca a centralidade de sua pesquisa na relação entre colônia e nação. Dessa forma, um dos seus principais eixos de discussão é a transição entre a situação colonial e a situação nacional. Para tanto, era necessário o diagnóstico da situação colonial. Caio Prado vê o Brasil Colônia formado no contexto da expansão ultramarina europeia, sendo uma colônia de exploração. Tais colônias teriam como característica a produção monocultora de bens de alto valor no mercado externo, organização produtiva em grandes unidades (grandes propriedades) e utilização preponderante de trabalho escravo. O sentido da colonização brasileira seria produção em larga escala de gêneros tropicais para o mercado mundial, como apresentado em Formação do Brasil contemporâneo.

Essa estrutura econômica teria consequências fortes sobre o Brasil, pois 
a sociedade e a economia se organizavam a partir desse objetivo externo e desconheciam as necessidades da população. Os homens e as poucas mulheres que para cá vieram da metrópole seriam movidos apenas por considerações mercantis, não pensariam em criar sociedade aqui, seriam aqueles que desejavam, sobretudo, ser dirigentes e não "meros" trabalhadores.

É a partir dessa avaliação da realidade histórica brasileira que Caio Prado propõe que as colônias de exploração se reduziam a uma "vasta empresa comercial", com ausência quase total de superestrutura: a escravidão estava baseada em relações de força. Lembrando-nos do estudo de Joaquim Nabuco, Caio Prado afirma que de fato não havia nenhuma lei que falasse de escravos. Simplesmente não havia referência do Estado à existência de escravos. Não havia nem mesmo um código negreiro que versasse sobre a administração e tratamento das condições de vida da população em condição de escravidão. Mas, de acordo com Martins (2017), havia amplo ordenamento jurídico em Portugal que visava regulamentar o trabalho do regime escravocrata na colônia e as questões econômicas, em especial fiscais, ligadas à exploração da escravidão.

Assim, a vida orgânica da colônia era ligada à grande exploração que produzia os bens demandados pelo mercado externo. Como as necessidades da população eram ignoradas para esse fim, o consumo dessa população era atendido pelo setor inorgânico. $\mathrm{O}$ setor inorgânico era aquele que não pertencia à grande exploração e a ela tinha papel subalterno.

A estrutura social colonial refletia essa divisão do setor orgânico da colônia:senhores rurais e escravos. Porém, com o tempo, vai aumentando o número daqueles cuja situação social é pantanosa, os "desclassificados", aqueles que não têm lugar nessa divisão social. É nesse grupo social crescente que Caio Prado deposita suas esperanças de transformação. Para ele, é esse grupo social que aponta para a orientação que a nação brasileira deve seguir no futuro.

Conforme já afirmamos, o conceito de nação é central na pesquisa do historiador paulista. Em sua concepção, a nação, para existir, deverá atender às necessidades internas da população. Porém, percebia que o Brasil tinha enormes dificuldades de constituir-se como nação, porque, mesmo após a independência, a orientação principal da vida brasileira continuava a estar voltada para fora. Mesmo assim, destaca o fato de que a formação do Estado Nacional marca uma nova fase na história brasileira.

$\mathrm{Na}$ formulação de Caio Prado, o movimento da transformação viria da contradição fundamental presente no Brasil de seu tempo: um desacordo entre o sistema econômico legado pela colônia e as novas necessidades de uma 
nação livre e politicamente emancipada. Era a contradição entre a estrutura econômica e a organização político-jurídica copiada dos Estados liberais do centro capitalista.

De nosso ponto de vista, a interpretação de Caio Prado sobre o Brasil deixa, além de toda uma nova perspectiva de história econômica, dois grandes legados para o pensamento econômico brasileiro. $\mathrm{O}$ primeiro se refere à sua visão sobre a continuidade com o passado, presente nas estruturas agrárias brasileiras e nas permanências escravistas nas relações sociais de produção. Por outro lado, revelou a necessidade de se pensar o Brasil como parte de um sistema mundial e não ficar em busca das idiossincrasias e individualidades do país, movimento preponderante das interpretações do Brasil até então.

\section{Conclusão}

O objetivo neste texto foi destacar no pensamento dos intérpretes do Brasil, das duas gerações analisadas (final do século XIX e anos 1920-1930), os elementos mais importantes que tivessem influenciado a origem do pensamento econômico brasileiro.

Nesse sentido, buscou-se enfatizar como alguns dos autores dessas duas gerações deram ênfase para as questões da estrutura produtiva, isto é, para as questões da produção e das relações sociais estruturais e superestruturais a ela relacionadas. Dessa forma, tais interpretações tratam de temas do campo da economia, e, em especial, da economia política, antes mesmo de haver uma formalização do conhecimento nessa área no Brasil. As formas pelas quais essas interpretações foram construídas variaram nos diferentes momentos históricos em que os autores realizavam suas análises, assim como variaram do ponto de vista teórico, mas todos colocavam suas interpretações a partir de uma perspectiva histórica e da estrutura econômica e social brasileira.

Os autores da primeira geração construíram sua análise tendo como cenário o processo de transição da estrutura do império escravocrata para o Brasil republicano, no qual haveria mudanças nas formas de organização do trabalho e das relações sociais de produção. Joaquim Nabuco organizou sua interpretação a partir das questões referentes ao processo de trabalho e da constituição do povo brasileiro, partindo da noção de que os escravos constituíam a maior classe formadora do povo no Brasil e que as mazelas relacionadas a suas condições de submissão e à ausência completa de direitos seriam questões problemáticas não somente para as pessoas escravizadas, mas para a 
formação da nação como um todo. Dessa forma, em sua análise, qualquer possibilidade de mudanças no processo de formação econômica e social brasileira teria que passar por alterações profundas na forma de organização do trabalho, bem como nos elementos superestruturais desta nação, que se articulam à estrutura econômica. Euclides, por sua vez, ia mais longe, afirmando que não bastava superar a forma escravista, mas era necessário definir uma forma de produção e de sociabilidade efetivamente correspondentes à realidade brasileira que, como em Canudos, caracterizava-se por ser uma forma de resistência. Em seu trabalho, destaca o sertanejo como o personagem histórico capaz de carregar a formação da nação autônoma.

A segunda geração analisada no texto parte da tentativa de compreender a formação econômica e social brasileira a partir do processo, que se iniciava naquele período, de transição de uma sociedade agrário-exportadora para uma sociedade urbano-industrial. Pode-se destacar nos três autores considerados emblemáticos três formas distintas de análise desse processo, tanto do ponto de vista teórico quanto do político e ideológico. Mas há elementos comuns em suas interpretações: nas três há a centralidade da análise no padrão de formação social brasileiro, assim como o diagnóstico do descolamento, naquele período, entre a estrutura produtiva de fato existente no Brasil e as formas institucionais aqui vigentes.

É possível destacar, sinteticamente, das interpretações desses autores alguns elementos que possuem articulação com o pensamento econômico brasileiro: Gilberto Freyre organiza sua interpretação em torno da análise da articulação entre a organização dos espaços privados (a família patriarcal, que é a base da sua caracterização do Brasil) com a estrutura de classe estabelecida a partir da forma de produção existente no Brasil. Sérgio Buarque de Holanda, por sua vez, traz como contribuição a percepção de que o Brasil se constitui como uma formação social nova, ainda que submetida à europeia, afirmando que as relações sociais de produção aqui existentes são específicas e que devem ser analisadas a partir de um método próprio. Por fim, Caio Prado Júnior é um dos primeiros autores a utilizar o referencial analítico marxista para a análise da situação do Brasil.Além disso, possui ampla influência na construção do pensamento econômico brasileiro, sendo algumas de suas formulações consideradas pilares da análise do processo histórico da economia brasileira. Destacamos como principais contribuições a sua noção sobre a continuidade na contemporaneidade do passado existente nas estruturas agrárias no Brasil e a percepção da importância de se analisar o Brasil como 
parte integrante de um sistema mundial, em detrimento da noção anteriormente prevalecente de análise do processo de formação brasileiro a partir, somente, de seu movimento interno.

Em suma, nossa pesquisa pretendeu encontrar nesses autores as discussões das estruturas econômicas e sociais brasileiras que ganham centralidade em suas visões sobre o Brasil e que dão origem ao campo de reflexão que será encampado pelo pensamento econômico brasileiro.

Conforme afirmou Lapa (1980), para analisarmos o pensamento econômico brasileiro engendrado por esse debate, precisamos perpassar diversos elementos,

[...] as acirradas discussões sobre a estrutura fundiária, a renda da terra e o lucro agrícola, o papel do Estado, a natureza das relações de produção, o desempenho das forças produtivas, a expropriação dos produtores diretos, a forma da propriedade (o proprietário fundiário e o capitalista), os fugidios processos de acumulação, a origem e/ou destino dos excedentes, o caráter e a dinâmica do capital, o alcance de sua dominação, o processo e condições da organização do trabalho, e por aí afora, se quisermos ficar ao nível econômico-social, têm-nos levado aos exercícios teóricos mais refinados para ajustá-los às nossas concepções conceituais e/ou a investigações empíricas - macro ou microeconômicas - objetivando surpreender dados concretos que nos remetam à reelaboração daquelas concepções. (Lapa, 1980, p. 20)

Propomos, então, que para continuar esta pesquisa e chegarmos à compreensão dos trabalhos dos intérpretes do Brasil, buscando acessar os elementos econômicos de seu pensamento, seria um bom método mergulhar em seus textos, sob a inspiração de Candido (1986), buscando encontrar:

a) sua visão sobre a população;

b) a forma como encaram o trabalho;

c) a maneira como descrevem a oligarquia;

d) seu modo de avaliar o imperialismo;

e) a forma como pensam a produção;

f) e sua concepção sobre a estrutura da sociedade.

Imaginamos que essas seriam boas chaves de acesso ao pensamento econômico brasileiro contido nas interpretações do Brasil e pretendemos explorá-las. 


\section{Referências}

BIELSCHOWSKY, R. (1988). Pensamento econômico brasileiro: o ciclo ideológico do desenvolvimentismo. Rio de Janeiro: Contraponto, 2000.

BOTELHO, A.; SCHWARCZ, L. Um enigma chamado Brasil: 29 intérpretes e um país. São Paulo: Companhia das Letras, 2009.

BOTELHO, A. Prefácio: Intérpretes do Brasil, nossos antepassados? In: RICUPERO, Bernardo. Sete lições sobre as interpretações do Brasil. São Paulo: Alameda, p. 9-18, 2008.

BUARQUE DE HOLANDA, S. (1936). Raízes do Brasil. São Paulo: Companhia das Letras, 2011.

BUARQUE DE HOLANDA, S. (1920). Ariel. In: BARBOSA, Francisco de Assis (Org.). Raízes de Sérgio Buarque de Holanda. Rio de Janeiro: Rocco, p. 43-46,1989

BUARQUE DE HOLANDA, S. (1926). O lado oposto e os outros lados. In: BARBOSA, Francisco de Assis (Org.). Raízes de Sérgio Buarque de Holanda. Rio de Janeiro: Rocco, p. 85-88, 1989.

CANDIDO,A. (1959). Formação da literatura brasileira: momentos decisivos. Belo Horizonte, Rio de Janeiro: Ed. Itatiaia Ltda., 1997.

CANDIDO, A. Radicalismos. Estudos Avançados, v. 4, n. 8, p. 4-18, 1986.

CANDIDO, A. (1967). O significado de raízes do Brasil. In: BUARQUE DE HOLANDA, S. Raízes do Brasil. São Paulo: Companhia das Letras, p. 9-21, 2008.

CARVALHO, M.A. R. de. André Rebouças e a questão da liberdade. In:BOTELHO, André; SCHWARCZ, Lilia Um enigma chamado Brasil: 29 intérpretes e um país. São Paulo: Companhia das Letras, p. 46-59, 2009.

COUTINHO, C. N. (1988). A imagem do Brasil na obra de Caio Prado Júnior. In: COUTINHO, Carlos Nelson. Cultura e Sociedade no Brasil - ensaios sobre ideias e formas. São Paulo: Expressão Popular, p. 219-241, 2011. 
CUNHA, E. (1902). Os Sertões. Rio de Janeiro: Nova Aguillar, 2000. (Coleção Intérpretes do Brasil)

CURTY, C.; MALTA, M. de M. Elementos metodológicos para a organização da história do pensamento econômico brasileiro: a abordagem das controvérsias. In: COSENTINO, Daniel do Val; GAMBI, Thiago Fontelas Rosado (Org.). História do pensamento econômico: pensamento econômico brasileiro. Niterói: EdUFF; Hucitec, p. 97-134, 2019. Coleção Novos Estudos de História Econômica do Brasil, v. 1.

FAORO, R. Existe um pensamento político Brasileiro? São Paulo: Editora Ática, 1994.

FERNANDES, F. (1975). A revolução burguesa no Brasil: ensaio de interpretação sociológica. São Paulo: Globo, 2005.

FREYRE, G. (1933). Casa Grande \& Senzala. Rio de Janeiro: Nova Aguillar, 2000. (Coleção Intérpretes do Brasil)

FURTADO, C. (1959). Formação econômica do Brasil. São Paulo: Companhia das Letras, 2006.

HOBSBAWM, E. O presente como história: escrever a história do seu próprio tempo. Novos Estudos Cebrap, n. 43, p. 103-112, 1995.

IGLÉSIAS, F. Celso Furtado, pensamento e ação. In: IGLÉSIAS, Francisco. História e ideologia. São Paulo: Perspectiva, p. 159-234, 1981.

LAPA, J. R. do A. Introdução ao redimensionamento do debate. In: LAPA, José Roberto do Amaral (Org.). Modos de produção e realidade brasileira. Petrópolis: Vozes, p. 9-42, 1980.

LIMA, N. T. Euclides da Cunha: o Brasil como sertão. In: BOTELHO, André; SCHWARCZ, Lilia. Um enigma chamado Brasil: 29 intérpretes e um país. São Paulo: Companhia das Letras, p. 104-117, 2009.

MARTINS, I. Sobre o camarada Caio Prado Júnior. A classe operária, p. 3, maio 1947. 
MARTINS, R. B.A obsessão com o tráfico, a legislação escravista e os códigos negreiros portugueses. XII CONGRESSO BRASILEIRO DE HISTÓRIA ECONÔMICA \& $13^{\text {a }}$ CONFERÊNCIA INTERNACIONAL DE HISTÓRIA DE EMPRESAS. Anais... Niterói: UFF/ABPHE, 2017.

MARX, K. (1859). Contribuição à crítica da economia política. São Paulo: Editora Expressão Popular, 2008.

MATTOS, M. B. Trabalhadores e sindicatos no Brasil. São Paulo: Expressão Popular, 2009.

NABUCO, J. (1884). O abolicionismo. Petrópolis:Vozes, 2012.

PERICÁS, L. B. Caio Prado Júnior: uma biografia política. São Paulo: Boitempo Editorial, 2016.

PINHEIRO, F. L.As origens da controvérsia da revolução brasileira: um debate entre Octavio Brandão, Mario Pedrosa e Lívio Xavier. Revista da Sociedade Brasileira de Economia Política, v. 51, p. 98-120, 2018.

PRADO JÚNIOR, C. (1933). Evolução Política do Brasil. São Paulo: Brasiliense, 2007.

PRADO JÚNIOR, Caio. (1942). Formação do Brasil contemporâneo. Rio de Janeiro: Nova Aguillar, 2000. (Coleção Intérpretes do Brasil)

RIBEIRO, D. (1995). O povo brasileiro: a formação e o sentido do Brasil. São Paulo: Companhia das Letras, 2013.

RIBEIRO, D. O processo civilizatório. Rio de Janeiro: Civilização Brasileira, 1968.

RICARDO, C. (1940). Marcha para Oeste: a influência da Bandeira na formação social do Brasil. Rio de Janeiro: José Olympio, 1970.

RICUPERO, B. Celso Furtado e o Pensamento Social Brasileiro. Estudos Avançados, v. 19, n. 53, 2005. 
RICUPERO, B. Sete lições sobre as interpretações do Brasil. São Paulo:Alameda, 2008.

RICUPERO, B. Caio Prado Júnior e o lugar do Brasil no mundo. In: BOTELHO, André; SCHWARCZ, Lilia. Um enigma chamado Brasil: 29 interpretações e um país. São Paulo: Companhia das Letras, p. 226-239, 2009.

SANTOS, W. G. Ordem burguesa e liberalismo político. São Paulo: Livraria Duas Cidades, 1978.

SCHWARZ, R. Ao vencedor as batatas. São Paulo: Livraria Duas Cidades, 1977.

SZMRECSÁNYI,T. Sobre a formação da Formação Econômica do Brasil de C. Furtado. Estudos Avançados, v. 13, n. 37, p. 207-214, 1999.

TEIXEIRA, A. Raízes do Brasil: o lado oposto e os outros lados. Revista Tempo Brasileiro, n. 149. p. 55-73, 2002.

VIANNA, O. (1920). Populações meridionais do Brasil. Rio de Janeiro: Nova Aguillar, 2000. (Coleção Intérpretes do Brasil)

WERNECK SODRÉ, N. A ideologia do colonialismo: seus reflexos no pensamento brasileiro. Rio de Janeiro: ISEB, 1961. 